\title{
Zastosowanie protez typu overdenture wspartych na belkach w leczeniu bezzębia żuchwy
}

\author{
Bar-supported overdentures in the treatment of edentulous mandible \\ ${ }^{1}$ Klinika Gerostomatologii, Uniwersytet Medyczny im. Karola Marcinkowskiego w Poznaniu \\ ${ }^{2}$ Klinika Protetyki, Uniwersytet Medyczny im. Karola Marcinkowskiego w Poznaniu
}

DOI: http://dx.doi.org/10.20883/df.2017.10

\begin{abstract}
Streszczenie
Niekorzystne warunki anatomiczne pola protetycznego, najczęściej istniejące w bezzębiu żuchwy, to problem złożony, wymagający ze strony lekarza umiejętnego i starannego leczenia. Istnieje kilka koncepcji leczenia bezzębnej żuchwy przy pomocy protez typu overdenture. W pracy przedstawiono, na podstawie piśmiennictwa, możliwości wykorzystania różnych rodzajów belek wspartych na implantach, stosowanych w celu poprawy retencji i stabilizacji protez całkowitych, a tym samym poprawiających pacjentom jakość życia.
\end{abstract}

Słowa kluczowe: overdenture, implanty, elementy precyzyjne.

\begin{abstract}
The unfavourable anatomical conditions of the prosthetic area that usually exist with edentulous mandible mean it is a complicated problem which requires skillful and careful treatment from the dentist. There are several approaches to using overdentures in the treatment of edentulous mandible. This paper presents, on the basis of the literature, the possibility of using implants to support various types of bars which are used to improve the retention and stabilization of the denture, and consequently to improve the patients Quality of Life.
\end{abstract}

Keywords: overdenture, implants, precision elements.

\section{Wprowadzenie}

Niekorzystne warunki anatomiczne pola protetycznego, istniejące najczęściej w bezzębiu żuchwy, to problem złożony, wymagający ze strony lekarza umiejętnego i starannego leczenia protetycznego. Rozwój biomechaniki i implantologii stomatologicznej umożliwiły opracowanie nowych metod postępowania u tej grupy pacjentów. Postęp, jaki dokonał się w dziedzinie biomechaniki, pozwolił na poznanie mechanizmów mających miejsce w obrębie jamy ustnej, rozkładu działających sił i obciążeń poszczególnych tkanek. Istnieje szereg metod badawczych, które umożliwiają przeprowadzanie bardzo wnikliwych badań. Szczególnie przydatne w stomatologii są badania, w których wykorzystuje się techniki CAD/CAM (Computer Aided Design/Computer Aided Manufacturing) [1], badania fotoelastyczne [2-4] i badania wytrzymałościowe [5]. Często zastosowanie znajduje również metoda elementów skończonych [6]. Za pomocą tej metody bada się w mechanice komputerowej (CAE - Computer Aided Engineering) wytrzymałość konstrukcji, symuluje odkształce- nia, naprężenia, przemieszczenia, przepływ ciepła oraz przepływ cieczy.

Dynamiczny rozwój implantologii z kolei przyczynił się do wprowadzenia nowych i ulepszonych materiałów oraz do optymalizacji kształtów wszczepów. Obecnie jako najlepszy materiał na śródkostne wszczepy należy traktować tytan. Biokompatybilne właściwości tytanu pozwoliły na opracowanie metody leczenia stomatologicznego polegającej na wszczepianiu w tkankę kostną pacjenta implantów i osadzaniu na nich uzupełnień protetycznych różnego typu. Z tego materiału produkowana jest obecnie ogromna ilość różnych form implantatów i całych zestawów implantacyjnych [7], choć można także zauważyć szerokie zainteresowanie innymi materiałami.

\section{Overdenture}

Protezy typu overdenture lub wg polskiej nomenklatury protezy nakładowe to ruchome uzupełnienia protetyczne, w których wykorzystuje się odpowiednio przygotowane, zachowane korzenie zębów własnych pacjenta lub śródkostne implanty. 
Ma to na celu uzyskanie lepszej retencji i stabilności rozwiązania protetycznego przez ograniczenie jej niekorzystnej ruchomości w pionie, jak i w poziomie. Z punktu widzenia biomechaniki w przypadku leczenia bezzębia jest to rozwiązanie bardzo pozytywne, gdyż pozwala na przekazywanie sił żucia poprzez implanty lub poprzez implanty i podłoże śluzówkowo-kostne, co powoduje bardziej fizjologiczny rozkład tych sił i ich ograniczone oddziaływanie na błonę śluzową i kość wyrostka zębodołowego. Skrócone zęby pozwalają ponadto na bardziej osiowe ich obciążenie.

Istnieje kilka koncepcji leczenia bezzębnej żuchwy przy pomocy protez typu overdenture. Zakładają one zakotwiczenie w kości dwóch do sześciu implantów, które mogą być zblokowane belką lub stanowić samodzielny element retencyjny. Niekiedy już pojedynczy implant jest wykorzystywany do poprawy retencji protezy całkowitej w żuchwie. Precyzyjny zaczep retencyjny składa się najczęściej z dwóch elementów: matrycy - osadzonej w protezie, i patrycy - połączonej z implantem. Bywa także odwrotnie, gdy patryca znajduje się $w$ protezie, a matryca umieszczona jest przy wszczepie. Dobre utrzymanie protez uzyskuje się dzięki wykorzystaniu sił tarcia między powierzchniami matrycy i patrycy.

Do wykonania elementów precyzyjnych stosuje się stopy metali szlachetnych, tytan, stal chromowo-niklową, stelity oraz tworzywa sztuczne [8].

\section{Połączenia kładkowe}

Wielu klinicystów uważa połączenia kładkowe (Rycina 1) za najlepsze spośród elementów precyzyjnych stosowanych przy konstrukcjach ruchomych. Pietruski uważa, że belki zapewniają protezom nakładowym najwyższą retencję $\mathrm{i}$ stabilizację oraz warunkują rozkład sił zgodny z osią wszczepów [9]. Assuncao w swoich badaniach porównywał rozkład naprężeń pomiędzy tradycyjną protezą całkowitą (grupa kontrolna), protezą typu overdenture wspartą na dwóch wszczepach połączonych belką oraz protezą typu overdenture wspartą na dwóch nie zblokowanych wszczepach [1]. Modele przygotowano przy użyciu programu AutoCAD. Ocena prowadzona była z zastosowaniem oprogramowania Ansys. Działano pionową siłą o wartości $100 \mathrm{~N}$, skierowaną na lewy pierwszy ząb trzonowy. Wyniki pokazały, że w protezie nakładowej wspartej na dwóch wszczepach połączonych belką występują mniejsze naprężenia niż w przypadku, gdy jest ona wsparta na dwóch nie zblokowanych implantach.

Istnieje kilka rodzajów belek, które różnią się profilem i mogą być produkowane fabrycznie lub wykonane indywidualnie przez technika. Ze

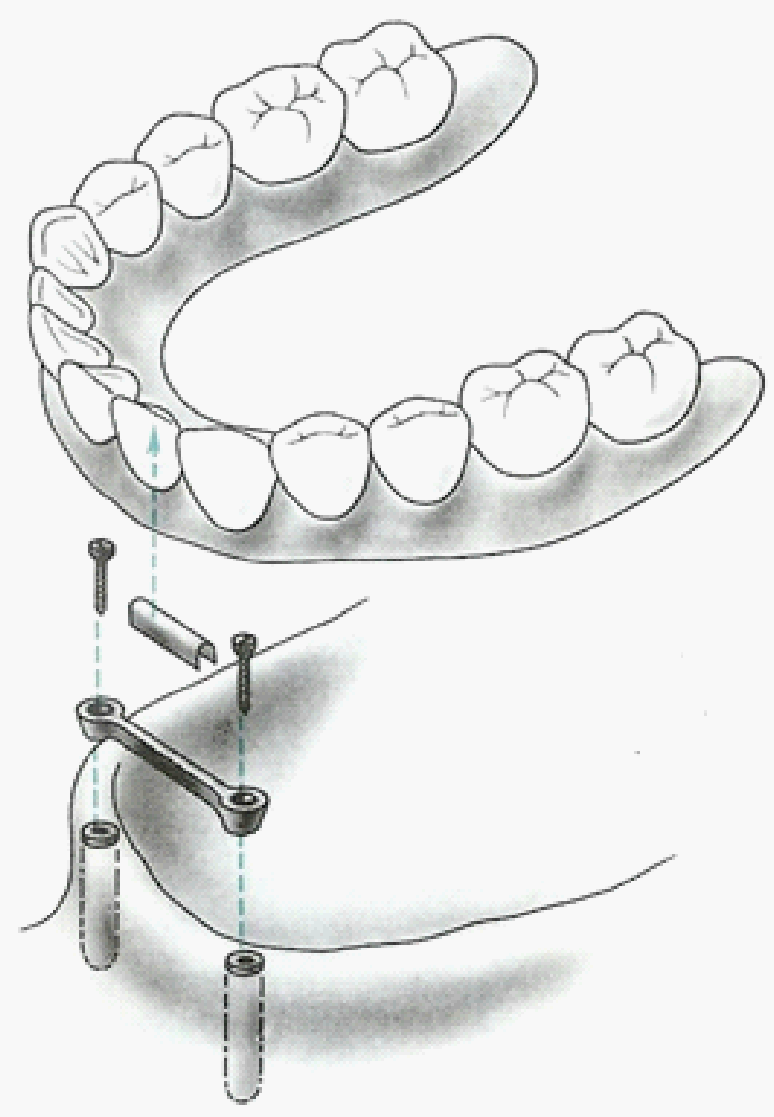

Rycina 1. Protetyczno-implantologiczna koncepcja leczenia bezzębnej żuchwy [7]

Figure 1. Prosthetic-implantological concept for the treatment of edentulous mandible [7]

względu na kształt przekroju belki połączenia te można podzielić na: okrągłe, owalne, równoległe i nietypowe, a ze względu na kształt połączenia filarów między implantami na: proste (2 implanty), łamane (większa ilość implantów) i nietypowe (kształt V, półokrągłe). Poszczególne typy różnią się od siebie zakresem swobody ruchu, jaki posiada oparta na nich proteza typu overdenture. W przypadku belek prostych o przekroju okrągłym proteza posiada największą swobodę ruchu. Okrągły kształt pozwala na ruchy obrotowe protezy wokół długiej osi samej belki. Obciążenia okluzyjne przenoszone są głównie na błonę śluzową podłoża protetycznego. Belki proste o ścianach równoległych i oporowym kształcie blokują obroty protezy, przenosząc siły okluzyjne w głównej mierze na implanty. Belki owalne można określić jako belki półsztywne, które przenoszą siły na implanty i struktury kostne pokryte błoną śluzową. Praktycznie wszystkie belki łamane są połączeniami typu sztywnego i szczególnie przy większej liczbie implantów można je porównać do mostów warunkowo ruchomych, gdzie wszystkie siły okluzyjne przenoszone są bezpośrednio na śródkostne wszczepy. 


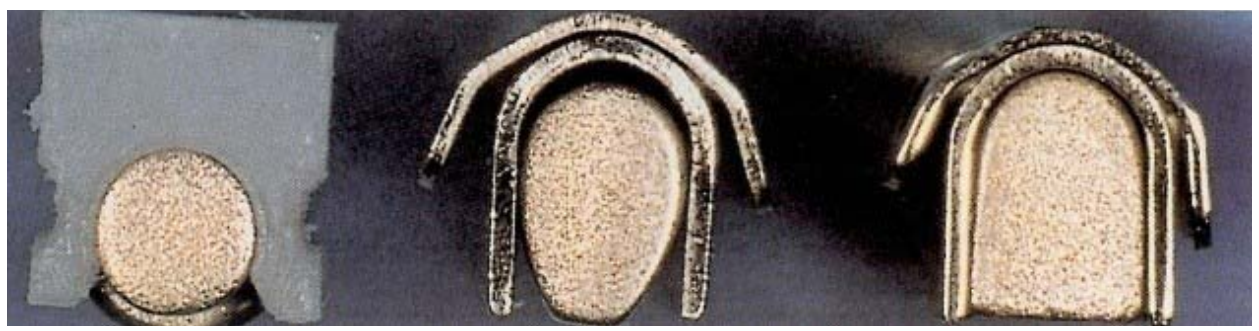

Rycina 2. Przekroje najczęściej stosowanych belek: belka okrągła (Hadera), belka owalna (Doldera), belka o ścianach równoległych [7]

Figure 2. Sections of most practical and often used bars: a round (Hader) bar, an oval (Dolder) bar, a bar with parallel sides [7]

Do najczęściej stosowanych połączeń kładkowych (Rycina 2) należą: kładka Doldera o przekroju owalnym, której sztywna struktura warunkuje rozmieszczenie jej między filarami w linii prostej; kładka Hadera - o przekroju poprzecznym w kształcie dziurki od klucza, który zapewnia podcień retencyjny dla matrycy typu ,jeździec" wykonanej z tworzyw sztucznych; kładka Ackermanna - o przekroju owalnym lub okrągłym, której elastyczna struktura umożliwia wyprofilowanie jej zgodnie z kształtem wyrostka zębodołowego [10].

Liczba implantów połączonych za pomocą belki może być zmienna i dla żuchwy waha się od jednego do sześciu. Najczęściej jednak stosuje się dwa lub cztery implanty jako filary pod protezę ruchomą (Rycina 3). W piśmiennictwie można znaleźć wiele doniesień popierających słuszność różnych koncepcji. Zakotwiczenie dwóch implantów w kości w okolicy kłów lub pierwszych przedtrzonowców i zblokowanie ich belką jest jednym z najprostszych rozwiązań, pozwalającym uzyskać bardzo dobre wyniki pod względem retencji i stabilizacji protezy [11]. Doświadczenia Gotfredsena pokazały, że jest to wystarczająca liczba wszczepów - po pięciu latach użytkowania w badanej grupie nie stwierdzono żadnego przypadku utraty implantu [12]. Alternatywą dla tej metody leczenia może być zastosowanie czterech wszczepów zakotwiczonych $w$ regionie interforamenalnym bezzębnej żuchwy i zblokowanie ich kładką. Koncepcja ta jest szczególnie korzystna w przypadku, gdy przedni odcinek żuchwy ma wąski łukowaty kształt [7]. Modyfikacją tego rozwiązania jest zastosowanie belki wydłużonej w kierunku dystalnym. Długość jednostronnie podpartych wypustek (cantilever bar) wynosić może do ok. $1 \mathrm{~cm}$ i nie powinna przekraczać okolicy pierwszego zęba przedtrzonowego [13]. Elsyad uważa, że optymalna długość wypustek to $7 \mathrm{~mm}$. Wówczas, w porównaniu z wypustkami o długości 9 i $11 \mathrm{~mm}$, generowane są najmniejsze naprężenia, bez znaczących różnic w kości wokół implantów [14]. Zaletą takiego rozwiązania jest większa stabilność i pewne zakotwiczenie protezy na konstrukcji kładkowej [7]. Obecnie zamiast tradycyjnych wypustek często stosuje się zatrzaski kulowe, umieszczone obustronnie, dystalnie do wszczepów.

Badania Sadowskiego oceniały wpływ liczby implantów na rozkład naprężeń. Oceniano protezy typu overdenture wsparte na belkach zaopatrzonych wypustkami, zakotwiczonych na dwóch lub trzech implantach. We wszystkich grupach uzyskano niewielkie obciążenie wszczepów, jednak najbardziej jednolity rozkład naprężeń uzyskano w przypadku protez wspartych na dwóch implantach [3].

Zastosowanie belki wspartej na trzech implantach może być korzystne, gdy żuchwa ma kształt litery V. Jeden implant zostaje wówczas umieszczony centralnie, a dwa symetrycznie po bokach, co pozwala na wyprofilowanie dojęzykowej powierzchni protezy. Ustawienie belek w kształcie litery $\mathrm{V}$ zapobiega znacznym ruchom rotacyjnym protezy i zmniejsza ryzyko powstawania przeciążeń [15].

Liczba implantów zależy w dużym stopniu od warunków podłoża protetycznego i ma na celu uzyskanie jak najkorzystniejszego rozkładu sił i obciążeń funkcjonalnych. Ważne jest, aby nie doprowadzić do zbyt wielkich naprężeń w kości wokół wszczepów, które mogłyby spowodować wcześniejszą ich utratę.

Dla prawidłowego rozkładu sił istotną rolę odgrywa też odpowiednie zakotwiczenie implantów w kości. Federick przeprowadził badania, w których oceniał obciążenie wszczepów w zależności od ich równoległej implantacji. Stworzył on dwa modele: $w$ jednym umieścił dwa implanty równolegle do linii pośrodkowej, w drugim implanty zostaty umieszczone rozbieżnie, pod kątem $17^{\circ}$ do linii pośrodkowej. Badania potwierdziły, że lepsze jest 

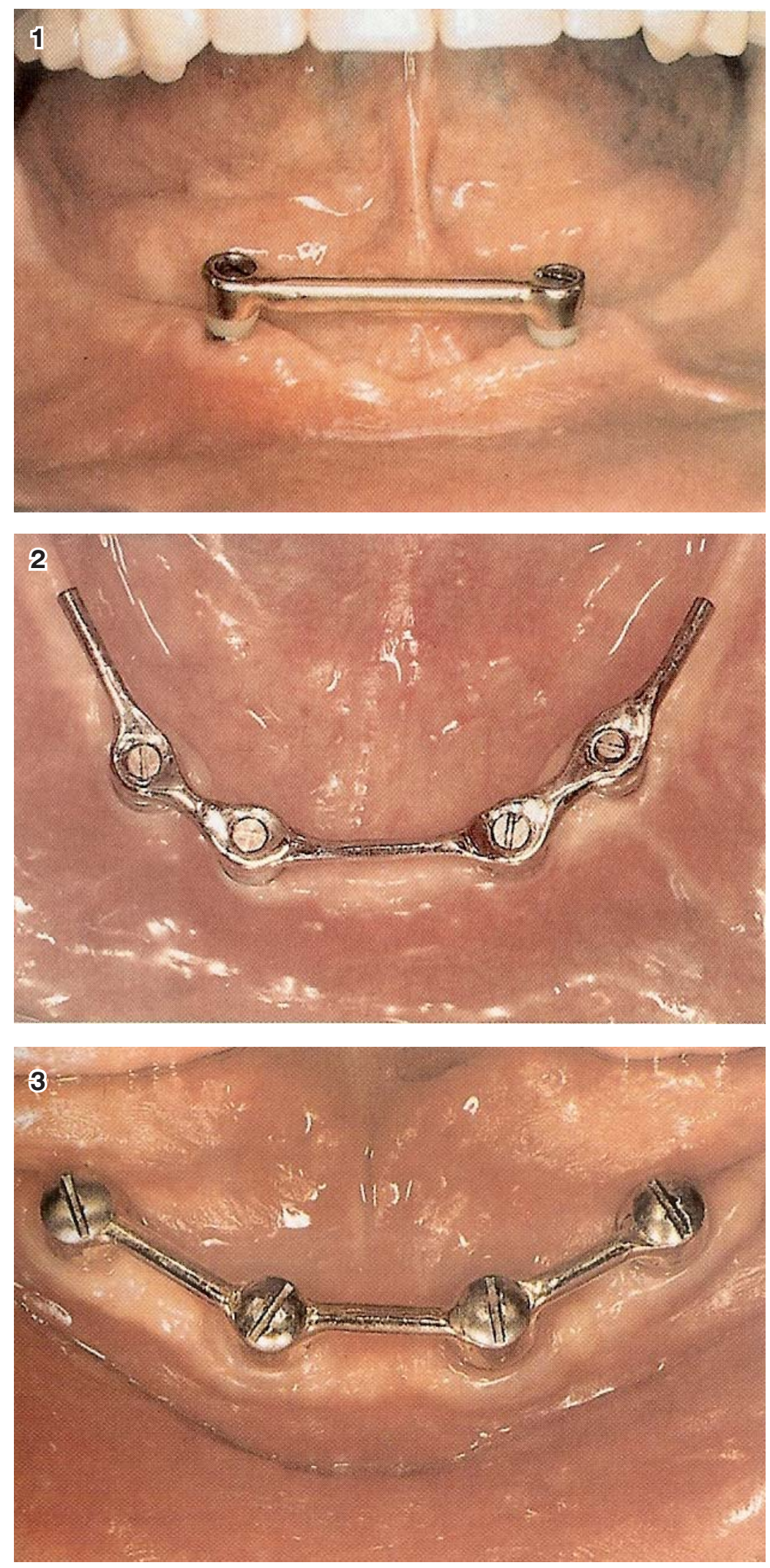

Rycina 3. 1. Belka wsparta na dwóch implantach, 2. Belka wsparta na czterech implantach, 3. Zmodyfikowana belka wsparta na czterech implantach z wypustkami w kierunku dystalnym [7]

Figure 3. 1. A bar supported on two implants, 2. A bar supported on four implants, 3. A modified bar supported on four implants with a cantilever bar 
równoległe rozmieszczenie implantów, przy którym obserwuje się mniejsze naprężenia [16].

Istotnym problemem pojawiającym się w przypadku stosowania protez typu overdenture jest zużycie elementów precyzyjnych, co wiąże się $z$ utratą retencji [17]. Przyczyną może być tutaj mała odporność tytanu na ścieranie. Za średni czas użytkowania matrycy polimerowej (z tworzyw sztucznych) przyjmuje się 1-2 lata. Badania Gotfredsena [18] pokazały, iż w ciągu trzech lat od osadzenia protez wspartych na belkach wymiana matryc dla przywrócenia retencji była konieczna w $73 \%$ przypadków. W sytuacji częściowego starcia powierzchni metalowej belki na skutek kontaktu z metalową patrycą typu „jeździec” lub kontaktu z tworzywem akrylowym można założyć matrycy polimerowej o zmniejszonej elastyczności [19].

\section{Podsumowanie}

W porównaniu z konwencjonalnymi protezami opartymi całkowicie na błonie śluzowej protezy typu overdenture charakteryzują się lepszym rozkładem sił na podłożu protetycznym. Protezy nakładowe zapewniają duży komfort użytkowania, gdyż cechuje je dobra retencja, stabilizacja i estetyka [20, 21]. Jest to możliwe dzięki zastosowaniu elementów precyzyjnych, którymi oprócz belek mogą być zatrzaski kulkowe, korony teleskopowe i magnesy, a także inne elementy retencyjne. Pacjenci łatwiej adaptują się do tego typu protez ze względu na poprawiony komfort żucia, artykulacji i mowy. Stopień zadowolenia pacjentów jest wysoki, choć wielu preferuje wykorzystanie połączeń kładkowych lub zatrzasków kulkowych niż magnesy [22]. Różnice pomiędzy belką a zatrzaskami kulkowymi nie są dla pacjentów odczuwalne. Należy jednak zaznaczyć, iż zaczepy kulkowe wymagają większej ilości napraw [23].

Przy planowaniu uzupełnień typu overdenture istotne jest prawidłowe rozmieszczenie implantów oraz zastosowanie pomiędzy nimi odpowiedniego rodzaju belki, co umożliwia korzystne rozłożenie działających sił, nie przeciążające filarów i zapewniające wystarczającą retencję. Pozwala to w znacznym stopniu zadowolić pacjenta i podnieść jego komfort życia w aspekcie stomatologicznym.

\section{Oświadczenia}

\section{Oświadczenie dotyczące konfliktu interesów}

Autorzy deklarują brak konfliktu interesów w autorstwie oraz publikacji pracy.

\section{Źródła finansowania}

Autorzy deklarują brak źródeł finansowania.

\section{Piśmiennictwo}

[1] Assuncao WG, Tabata LF, Barao VAR, Rocha EP. Comparison of stress distribution between complete denture and implant-retained overdenture-2D FEA. Journal of Oral Rehabilitation. 2008;35:766-774.

[2] Kenney R, Richards MW. Photoelastic stress patterns produced by implant-retained overdentures. The Journal of Prosthetic Dentistr. 1998 Nov;80(5):559-564.

[3] Sadowsky SJ, Caputo AA. Stress transfer of four mandibular implant overdenture cantilever design. The Journal of Prosthetic Dentistr. 2004 Oct;92(4):328-336.

[4] Thompson WD, Kratochvil FJ, Caputo AA. Evaluation of photoelastic stress patterns produced by various design of bilateral distal- extension removable partial dentures. The Journal of Prosthetic Dentistr. 2004 Feb;91(2):105113.

[5] Svetlize CA, Bodereau EF. Comparative study of retentive anchor systems for overdentures. Quintessence Int. 2004 Jun;35(6):443-8.

[6] Chladek W, Chladek G, Krukowska J, Lipski T. Stress distribution In anchoring regions of posts cooperating with overdentures. Acta of Bioengineering and Biomechanic. 2005;7:1.

[7] Hupfauf L. Protetyka stomatologiczna. W: Płonka B. (red.). Protezy całkowite. Wyd. I. Wrocław: Urban \& Partner; 1994.

[8] Kubiak W, Grodecki P. Niektóre elementy precyzyjne stosowane w protetyce stomatologicznej - przegląd piśmiennictwa. Prot Stomat. 1998;48:17-26.

[9] Pietruski J, Pietruska M, Stokowska W, Pattarelli M. Protezy overdenture - wybrane możliwości zastosowania w rehabilitacji narządu żucia. Czas Stomat. 2001;54: 461-468.

[10] Koczorowski R, Brożek R, Hemerling M. Wykorzystanie elementów precyzyjnych $\mathrm{w}$ leczeniu implantoprotetycznym. Dent Med Probl. 2006;43(3):421-428.

[11] Timmerman R, Stoker GT, Wismeijer D, Oosterveld P, Vermeerern JI, van Waas MAJ. An eight-year follow-up to a randomized clinical trial of participant satisfaction with three types of mandibular implant-retained overdentures. J Dent Res. 2004;83(8):630-633.

[12] Gotfredsen K, Holm B. Implant-supported mandibular overdentures retained with ball or bar attachments: a randomized prospective 5-year study. Int J Prosthodont. 2000 Mar-Apr;13(2):125-130.

[13] Mericske-Stern R, Taylor T. Belser U. Management of the edentulous patient. Clin Oral Impl Res. 2000;11:108-125.

[14] Elsyad MA, Al-Mahdy YF, Salloum MG, Elsaih EA. The effect of cantilevered bar length on strain around two implants supporting a mandibular overdenture. Int $\mathrm{J}$ Oral Maxillofac Implants. 2013;28:143-50.

[15] KoczorowskiR, SurdackaA, BrożekR. Doświadczeniawłasne z protezami bezzębnej żuchwy opartymi na wszczepach śródkostnych. Dental Forum. 2005;32(2):7-16.

[16] Federick DR, Caputo AA. Effects of overdenture retention designs and implant orientations on load transfer characteristics. J Prosthet Dent. 1996;76:624-632.

[17] Rzątowski S. Analiza wartości siły retencji zewnątrz koronowych precyzyjnych elementów utrzymujących. Rozprawa na stopień doktora nauk med. Poznań 2008.

[18] Gotfredsen K. Implant supported overdentures - the Copenhagen experience. J Dent. 1997;25(Supl.):39-42.

[19] Choy E, Reimer D. Laboratory processing of housing-retained attachments for implant-supported overdentures. J Prosthed Dent. 2001;85:516-519.

[20] Koczorowski R. Całkowite protezy nakładowe oparte na strukturach belkowych implantów śródkostnych. Dental Forum. 2016;XLIV(2):65-72.

[21] Koczorowski R. Geroprotetyka - rekonstrukcje narządu żucia u osób starszych. Med Tour Pres; 2010.

[22] Cune M, van Kampen F, van der Bilt A, Bosman F. Patient satisfaction and preference with magnet, bar-clip, and ball-socket retained mandibular implant overdentures: 
a cross-over clinical trial. Int J Prosthodont. 2005 Mar-Apr;18(2):99-105.

[23] MacEntee MI, Walton JN, Glick N. A clinical trial of patient satisfaction and prosthodontic needs with ball and bar attachments for implant-retained complete overdentures: three-year results. J Prosthet Dent. 2005 Jan;93(1):28-37.

Zaakceptowano do edycji: 2017-04-12 Zaakceptowano do publikacji: 2017-04-22
Adres do korespondencji:

Klinika Gerostomatologii UMP

ul. Bukowska 70, 60-812 Poznań

tel.: +48 602865619

e-mail: mgidzior@poczta.onet.pl 